\title{
Skeletal Muscle Dysfunction: From Chronic Respiratory Disease to Critically III Patients
}

\section{Esther Barreiro, MD PhD}

Respiratory Medicine Department, Muscle Wasting and Cachexia in Chronic Respiratory Diseases and Lung Cancer Research Group, Institute of Medical Research of Hospital del Mar (IMIM), Barcelona, Spain; Centro de Investigación en Red de Enfermedades Respiratorias (CIBERES), Instituto de Salud Carlos III, Madrid, Spain

\section{ABSTRACT}

Muscle dysfunction, defined as the loss of either strength or endurance properties of muscles, is a prominent comorbidity in chronic obstructive pulmonary disease (COPD) that leads to impairment of the patients' exercise capacity and quality of life. Chronic obstructive pulmonary disease skeletal muscle dysfunction may affect both respiratory and limb muscles. However, the latter are usually more severely affected. Importantly, survival and COPD mortality are negatively influenced by dysfunction of the lower limb muscles and poor muscle mass as measured by mid-thigh cross-sectional area. In the current review, we discuss the effects of skeletal muscle dysfunction and wasting on the outcome of COPD. Additionally, whether muscle dysfunction takes place in respiratory disorders other than COPD, such as cystic fibrosis, idiopathic pulmonary fibrosis, scoliosis, and pulmonary arterial hypertension along with critical illness, is also reviewed herein. Identification of skeletal muscle dysfunction should be included in the routine assessment of patients with chronic respiratory disorders and in critical care settings and should be considered as a relevant target for treatment. (BRN Rev. 2016;2:129-42) Corresponding author: Esther Barreiro, ebarreiro@imim.es

Key words: Biological mechanisms. COPD. Critical illness. Muscle dysfunction. Other chronic respiratory diseases.

Correspondence to:

Esther Barreiro

E-mail: ebarreiro@imim.es
Received in original form: 11-04-2016 Accepted in final form: 11-05-2016 DOI: 10.23866/BRNRev:2016-M0022 


\section{INTRODUCTION}

In the coming decade, chronic obstructive pulmonary disease (COPD) will clearly be a major leading cause of death worldwide ${ }^{1,2}$. Muscle dysfunction, defined as the loss of either strength or endurance properties of muscles, is also a prominent condition in COPD that leads to impairment of the patients' exercise capacity and quality of life (Fig. 1) ${ }^{3}$. Other factors and conditions, such as muscle wasting, malnutrition, chronic heart failure, exacerbations, and reduced physical activity, may further deteriorate muscle function in COPD patients ${ }^{3,4}$. Despite that COPD skeletal muscle dysfunction may affect both respiratory and limb muscles, the latter are usually more severely affected. These are clinically relevant features as survival and COPD mortality are negatively influenced by both dysfunction of the lower limb muscles and poor muscle mass as measured by midthigh cross-sectional area ${ }^{3,5-7}$. Moreover, exacerbations rapidly induce loss of muscle force and activate different pathways, leading to muscle wasting and dysfunction; this may contribute to increasing the risk of hypercapnic respiratory failure, exercise limitation, and even death in patients with $\mathrm{COPD}^{8}$. In the current article, muscle dysfunction of the lower limbs and that of the respiratory muscles are reviewed independently.

Whether muscle dysfunction also takes place in other chronic respiratory conditions with low-grade systemic inflammation remains an open question as very few studies have been conducted to explore this problem. Indeed, evidence on the occurrence of respiratory or lower limb muscle weakness in respiratory diseases other than COPD is still in its infancy, thus

\section{Skeletal muscle dysfunction}

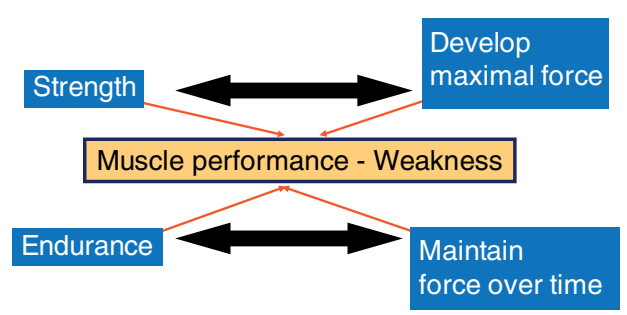

Figure 1. Schematic representation on how the two main properties of skeletal muscle contraction (strength and endurance) determine muscle performance or weakness when a significant reduction in muscle force generation (the most commonly studied parameter in COPD patients) occurs. COPD: chronic obstructive pulmonary disease.

emphasizing its role as a model to study muscle dysfunction in other respiratory conditions. In the last two decades, COPD muscle dysfunction has drawn most of the investigators' attention, probably as a consequence of the high prevalence of this condition as well as the socioeconomic burden of the costs related to the patients' management and treatment. Nevertheless, current evidence suggests that muscle dysfunction and weakness may also be a relevant comorbidity in patients with lung diseases other than COPD, which warrants special attention in future investigations. Furthermore, critically ill patients also experience muscle mass loss and weakness that negatively influence the patient's prognosis and quality of life after intensive care unit (ICU) discharge $e^{8,9}$.

In the current review, we discuss the effects of skeletal muscle dysfunction and wasting on the outcome of COPD. On the other hand, whether muscle dysfunction takes place in respiratory disorders other than COPD, such as cystic fibrosis, idiopathic pulmonary fibrosis, 
scoliosis, pulmonary arterial hypertension, and critical illness, is also briefly reviewed herein.

\section{SKELETAL MUSCLE DYSFUNCTION IN COPD}

Poor muscle function and mass loss are common systemic manifestations in COPD patients. In general, poor muscle mass and lower limb muscle dysfunction, as assessed by mid-thigh cross-sectional area and quadriceps weakness (defined as a decline in the ability to generate force), respectively, strongly influence exercise capacity and quality of life $\mathrm{e}^{10-12}$. Additionally, muscle weakness and atrophy lead to an increase in the use of healthcare resources ${ }^{13}$ and are predictors of survival and mortality in patients with COPD ${ }^{5-7}$.

In general, muscles of the lower limbs in COPD patients exhibit greater susceptibility to fatigue than age-matched healthy subjects ${ }^{14-18}$. Strength and endurance properties are impaired in the lower limb muscles of patients with COPD (Fig. 1) ${ }^{19-22}$. Although strength is not the most sensitive measure to evaluate muscle function in patients, it is commonly used in clinical settings as it can be easily measured in patients.

Quadriceps muscle dysfunction was a relevant manifestation in approximately one third of the COPD patients, even at very early stages of their disease, as demonstrated in a multicenter European-based study ${ }^{23}$. The proportion of patients with muscle weakness was identical in the different participating countries regardless of the patients' airway obstruction $^{23}$. The prevalence of muscle weakness among the patients did not significantly correlate with disease severity as measured by Global Initiative for COPD (GOLD) grades ${ }^{23}$. Nonetheless, the prevalence of COPD muscle weakness was associated with BODE (body mass index, airflow obstruction, dyspnoea, exercise capacity) and dyspnoea scores ${ }^{23}$. In another study, quadriceps strength and rectus femoris cross-sectional area were also significantly reduced in a cohort of 161 COPD patients that were evenly distributed from GOLD grades 1-4 compared to a population of age-matched healthy controls ${ }^{6}$. Furthermore, the decrease in endurance of lower limb muscles in COPD patients with normal physical activity and mild-to-moderate disease did not correlate with airway obstruction or quadriceps muscle weakness as demonstrated in another investigation ${ }^{16}$. The study also concluded that lower limb muscle endurance was reduced in COPD patients, even in those with a mild disease, and that such a decrease may precede strength impairment of the same muscles in COPD ${ }^{16}$. Collectively, the reported findings put forward the line that in COPD patients, impairments in muscle function (strength and/or endurance) are independent of the airway obstruction or lung function status. Therefore, skeletal muscle function should be evaluated in all patients with COPD, irrespective of the severity of the lung disease.

In COPD, despite that the respiratory muscles undergo a positive adaptation (training-like effect) that renders them more fatigue-resistant $22,24,25$, maximal inspiratory and expiratory pressures (strength) and endurance of these muscles were consistently reduced in the patients ${ }^{22,24-27}$. Respiratory muscle dysfunction imposes ventilatory constraints on 
patients that may worsen the underlying chronic respiratory failure frequently present in COPD patients, especially in advanced stages. Furthermore, respiratory muscle dysfunction constitutes an important factor, accounting for an increased risk of hospital readmissions ${ }^{28}$. On the other hand, acute exacerbations represent a major systemic contributor that equally affects both limb and respiratory muscles in patients with $\mathrm{COPD}^{8,29}$. Specifically in the ventilatory muscles, the need of these muscles to overcome the inspiratory loads imposed by the increased ventilatory demands resulting from the acute exacerbation may even further impair respiratory muscle strength.

\section{MULTIFACTORIAL AETIOLOGY OF MUSCLE DYSFUNCTION IN COPD: FACTORS AND MECHANISMS}

Several factors and biological mechanisms have been shown to participate in the multifactorial aetiology of respiratory and limb muscle dysfunction in COPD. Cigarette smoke, hypoxia, hypercapnia and acidosis, metabolic alterations of several types, malnutrition, genetics, systemic inflammation, aging, comorbidities, concomitant treatments, exacerbations, and inactivity are counted among the most relevant aetiological factors that contribute to muscle dysfunction in COPD patients through the action of several biological mechanisms. The contribution of several factors and mechanisms, such as structural abnormalities, muscle remodelling, oxidative stress and muscle wasting, epigenetic regulation of muscle mass and function, autophagy, and metabolic derangements, has been discussed in previously published reviews 3,19-22,24. Interestingly, the biological mechanisms involved in the pathophysiology of muscle dysfunction have been predominantly studied in the vastus lateralis of the quadriceps and in the diaphragm of patients with COPD. A brief summary of the most relevant aetiological factors and mechanisms in both muscle types follows.

\section{Quadriceps Muscle Dysfunction}

Cigarette smoke, genetics, hypoxia, hypercapnia and acidosis, metabolic derangements including vitamin D and testosterone deficiencies, medications (systemic corticosteroids), other comorbidities, exacerbations, systemic inflammation, nutritional abnormalities, reduced physical activity, and aging are all aetiological factors that clearly contribute to muscle dysfunction of the lower limbs in COPD ${ }^{3,19-22}$ (Fig. 2). Nevertheless, the predominance of physical inactivity ${ }^{6}$, nutritional abnormalities $^{4,19}$, repeated exacerbations ${ }^{8,29-31}$, and systemic corticosteroids ${ }^{32}$ should be underscored above the other factors as the main contributors to muscle function and mass impairment, especially in advanced COPD.

As depicted in figure 3, several molecular and cellular events take place in the lower limb muscles, which mediate the effects of the different aetiological factors in patients, leading to modifications in the muscle phenotype and function. A fibre-type switch towards a less fatigue-resistant phenotype (from slow-twitch to fast-twitch fibres) is a major feature in the vastus lateralis of patients with advanced COPD ${ }^{33-36}$. Furthermore, fast-twitch fibres are also of smaller size in patients with advanced COPD and poor muscle mass ${ }^{33-35}$, thus contributing to 


\section{Aetiology of muscle dysfunction in COPD}

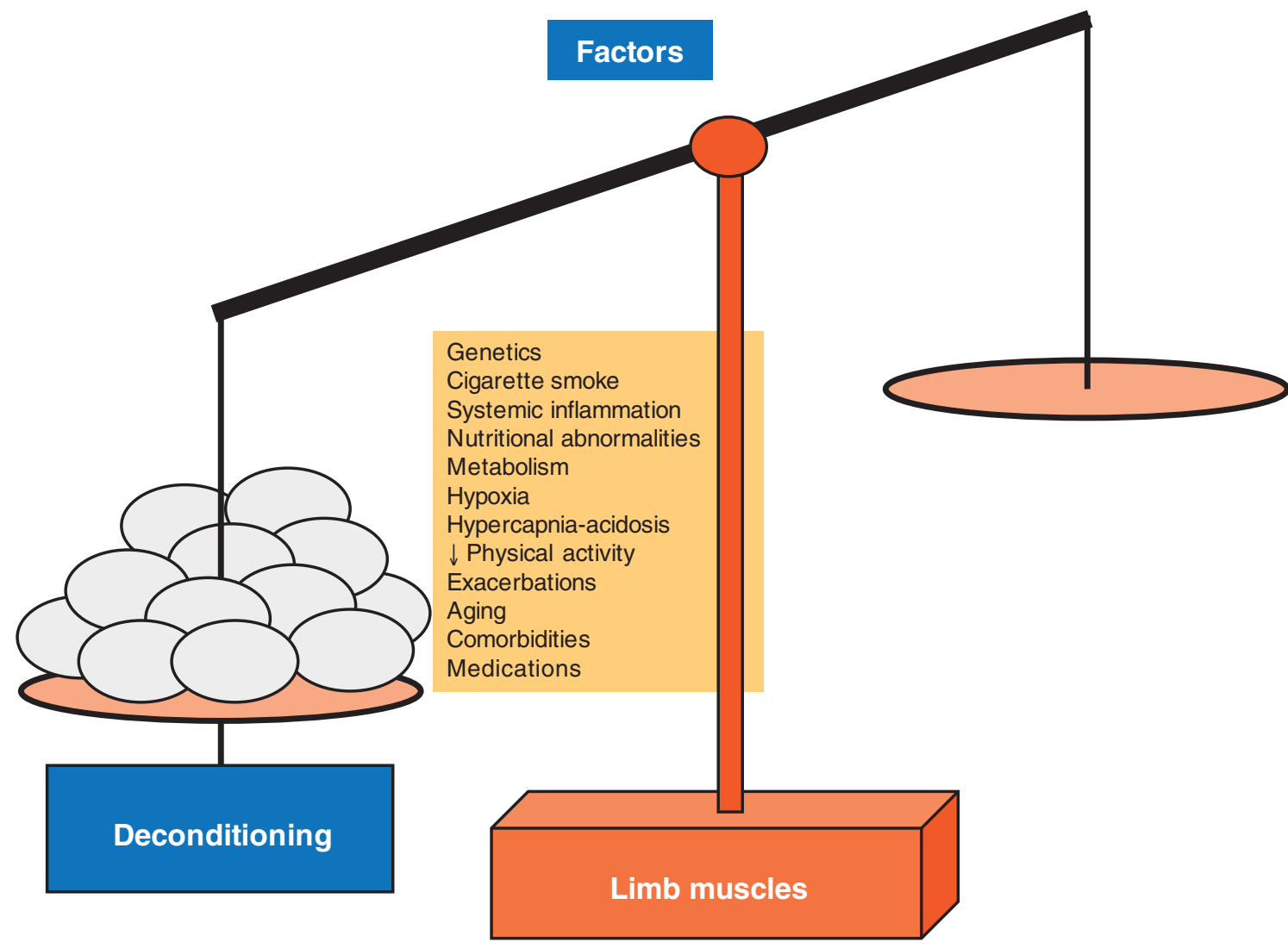

Figure 2. Several aetiological factors involved in the multifactorial aetiology of muscle dysfunction exert deleterious effects on the function and mass (deconditioning) of lower limb muscles in patients with COPD. Hence, the balance is completely skewed towards the negative side.

COPD: chronic obstructive pulmonary disease.

muscle weakness. Additionally, factors such as aging $^{37}$, malnutrition ${ }^{38}$, and systemic corticosteroid treatment ${ }^{39}$ may worsen the fasttwitch fibre atrophy observed in COPD. Besides, a reduction in the capillary numbers and contacts ${ }^{40,41}$ that could eventually impair oxygen delivery to the myofibers ${ }^{42-44}$ is another contributing biological mechanism. Other structural abnormalities, such as muscle cell membrane and sarcomere damage, may also negatively influence muscle function ${ }^{35}$. Mitochondrial derangements of several types were also demonstrated to alter muscle function in COPD ${ }^{45-47}$ (Fig. 3).

Chronic hypoxia induced a reduction in muscle mass, probably as a result of the interaction of several molecular mediators such as 


\section{Aetiology of muscle dysfunction in COPD}

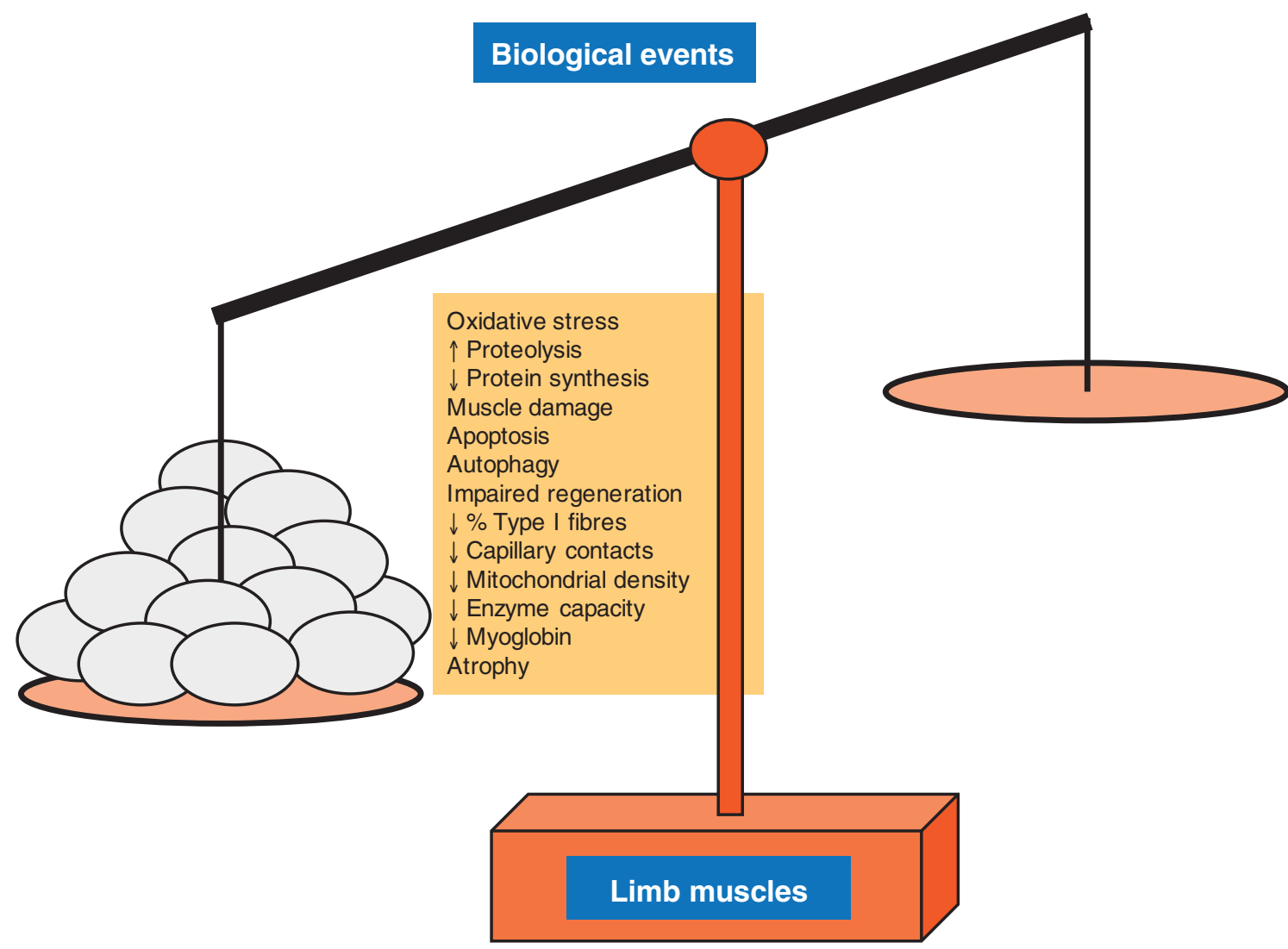

Figure 3. In lower limb muscles, several biological events that mediate the actions of the aetiological factors exert direct deleterious effects on muscle function, structure, and mass. Hence, the balance is completely skewed towards the negative side.

COPD: chronic obstructive pulmonary disease.

inflammation ${ }^{48}$, hypoxia inducible factor-1 signalling pathway ${ }^{49}$, oxidative stress ${ }^{50,51}$, and reduced oxidative enzyme capacity and capillary numbers ${ }^{36,52}$. Hypercapnia, which may worsen during exacerbations, may also play a role in COPD muscle dysfunction through acidosis as it enhances ubiquitin-proteasome proteolytic system activity and/or through a reduction in protein anabolism ${ }^{53}$ (Fig. 3).
Oxidative stress, defined as the imbalance between oxidants and antioxidants, and as measured by several markers, such as protein oxidation and nitration and lipid peroxidation, has been consistently shown in blood and limb muscles of patients with severe COPD both at rest and after exercise $33,35,51,54-61$. Importantly, oxidative stress markers were also shown to inversely correlate with several 
clinical and physiological parameters such as exercise capacity, body composition, and quadriceps strength of the patients $33,35,56,57,61$ (Fig. 3). Although oxidative stress and inflammation have been previously associated, evidence shows that local inflammatory events do not seem to occur in muscles of COPD patients $33,35,51,56,58,61,62$, even in atrophying muscles or during exacerbations.

Cigarette smoke may also contribute to limb muscle dysfunction in COPD through several biological mechanisms such as decreased type I fibre sizes and proportions and reduced mitochondrial activity, while concomitantly causing an increase in oxidative stress levels in healthy smokers and experimental animal models of chronic exposure to cigarette $\operatorname{smoke}^{58,63,64}$ (Fig. 1). Other relevant molecular and cellular events that have been shown to mediate muscle mass loss and dysfunction in COPD from different aetiological factors are increased proteolysis $^{33,35}$, apoptosis ${ }^{62}$, epigenetic mechanisms $^{34,65-68}$, and increased autophagy ${ }^{35}$ (Fig. 3).

\section{Diaphragm Muscle Dysfunction}

In COPD, since the respiratory muscles are chronically exposed to the inspiratory loads and must remain active throughout the life of patients, they are less severely affected than the lower limb muscles. In the last years, respiratory muscles have been studied through the analyses of the costal diaphragm, with very restricted access, and only via thoracotomy performed for clinical reasons (mainly lung cancer and lung volume reduction surgeries).
In COPD patients, modifications in ventilatory mechanics as a result of static pulmonary hyperinflation, which modifies thorax geometry and shortens the diaphragm length, displace the muscle away from its optimal length to generate the required forces ${ }^{19-22}$. Additionally, their respiratory muscles need to overcome the increased work of breathing resulting from the greater elastic, resistive, and threshold inspiratory loads imposed by airflow limitation ${ }^{19-22}$. These factors, which are inherent to the respiratory condition (ventilatory mechanics alterations), constitute the main contributors to respiratory muscle dysfunction in COPD (Fig. 4). However, it has also been shown that in COPD patients, the respiratory muscles somehow undergo a positive adaptation (training-like effect) that renders them (especially the diaphragm) more fatigue-resistant compared to diaphragm forces developed by healthy subjects when exposed to identical lung volumes $^{19-22}$ (Fig. 4). Finally, similar aetiological factors involved in the dysfunction of the lower limb muscles may also affect, to different degrees, the respiratory muscles in COPD: cigarette smoke, hypoxia, hypercapnia and acidosis, metabolic derangements, malnutrition, genetics, systemic inflammation, aging, comorbidities, concomitant treatments, exacerbations, and reduced physical activity ${ }^{3,19-22}$ (Fig. 4). However, in COPD, respiratory muscle dysfunction, exacerbations, nutritional abnormalities, and aging are likely to play a key role above the other contributing factors ${ }^{3,19-22}$.

As illustrated in figure 5, several molecular and cellular events that take place in the lower limb muscles also seem to mediate the effects of the different aetiological factors that negatively influence phenotype and function in the respiratory muscles. Nonetheless, specific 


\section{Aetiology of muscle dysfunction in COPD}

\section{Factors}

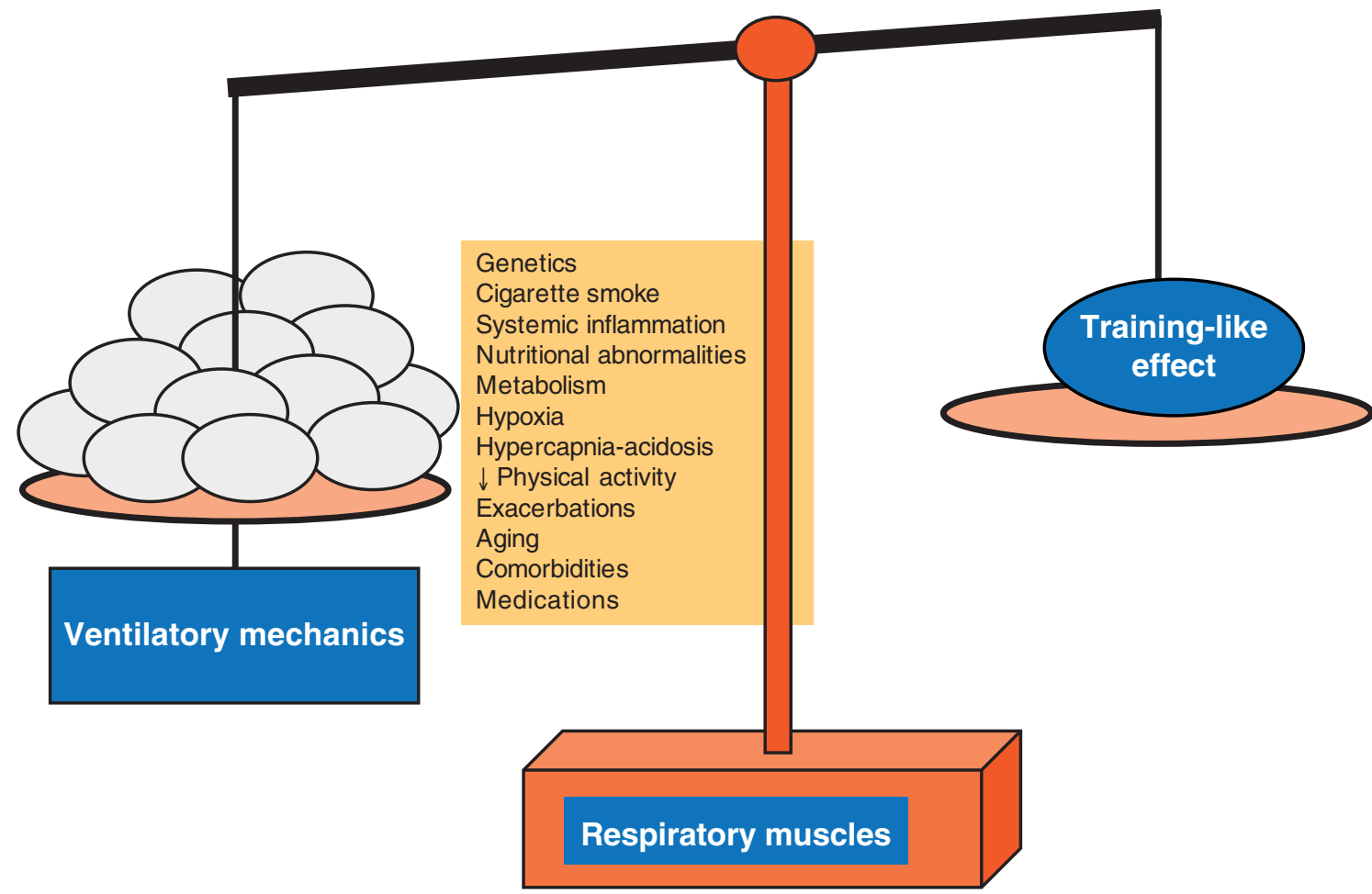

Figure 4. Schematic representation on how the different reported aetiological factors contribute to respiratory muscle dysfunction in COPD through the action of several biological mechanisms that modify muscle phenotype and function in patients. Notice that in COPD respiratory muscle dysfunction, as opposed to dysfunction of the lower limb muscles, several aetiological factors may exert beneficial effects (training-like effect) on muscle mass and performance through the action of different biological mediators (adaptive mechanisms) that lead to adaptation of the inspiratory muscles in COPD. These adaptive mechanisms partly counterbalance the deleterious effects of other factors and mechanisms of a rather systemic nature (depicted in the left-hand side of the figure).

COPD: chronic obstructive pulmonary disease.

cellular and molecular events also mediate beneficial effects (adaptive biological mediators) on the diaphragm of COPD patient such as shorter sarcomere length, higher proportions of slow-twitch fibres and myoglobin content, increased capillary contacts per fibre, increased mitochondrial density, and enhanced aerobic enzyme capacity (see specific reviews ${ }^{19-22}$ ) (Fig. 5). On this basis, the adaptive mechanisms may offset, to a certain extent, the adverse phenotypic features in the diaphragm of patients with COPD. In these patients, the final respiratory muscle outcome will rely on the balance between deleterious and adaptive 


\section{Aetiology of muscle dysfunction in COPD}

\section{Biological events}

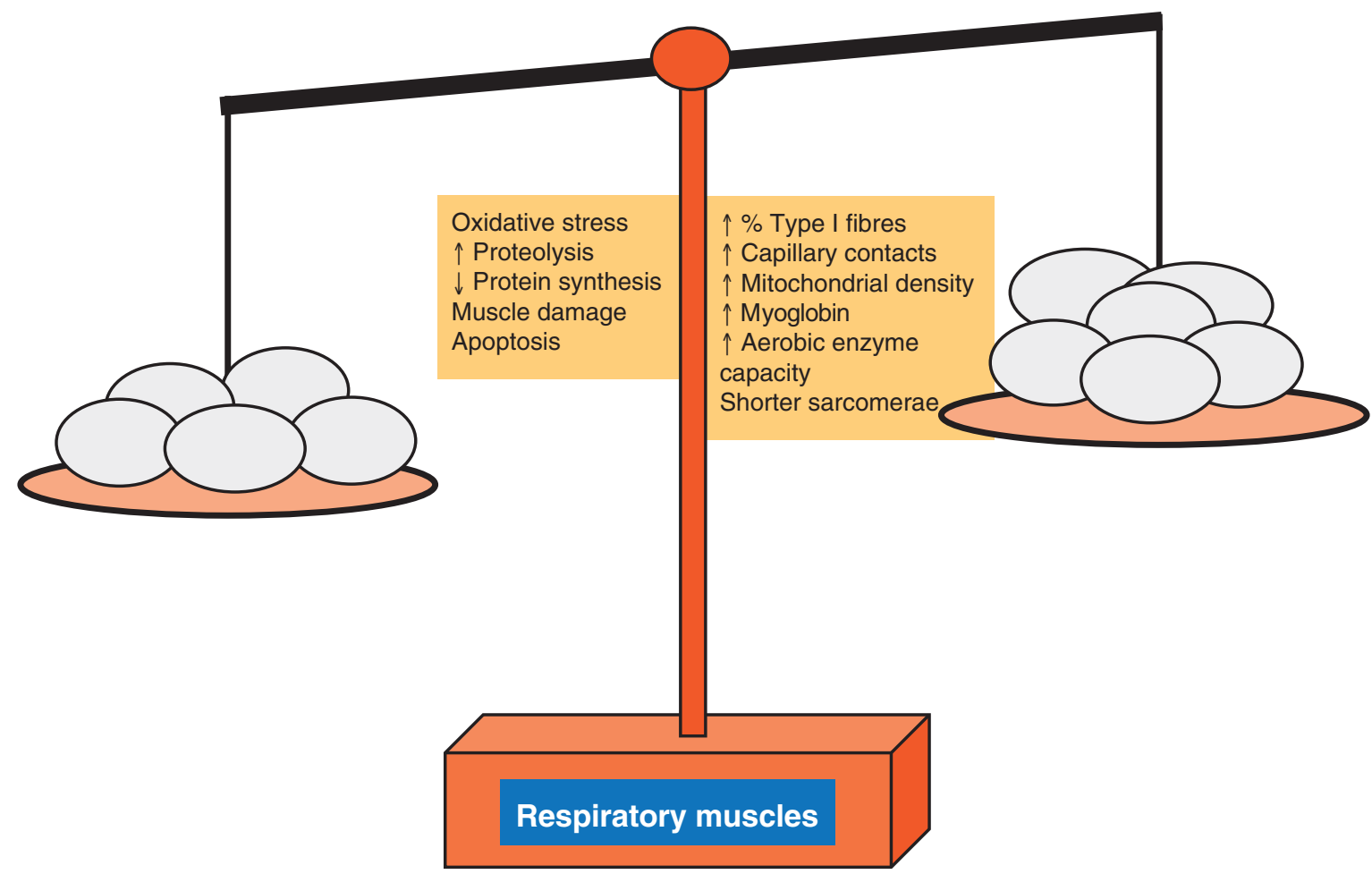

Figure 5. In the respiratory muscles, several cellular and molecular mechanisms exert beneficial effects (adaptive mechanisms, righthand-side tray), which partly counterbalance the deleterious actions of other biological events (left-hand-side tray).

COPD: chronic obstructive pulmonary disease.

biological mediators (Fig. 5), which may also differ between stable and acute conditions within the same patient. Interestingly, in the external intercostal muscle of COPD patients, similar adaptive cellular events may also take place $^{19-22}$. In advanced COPD, however, biological mechanisms concomitantly affecting the lower limbs, such as injury, oxidative stress, enhanced proteolysis and reduced anabolism, apoptosis, and epigenetic events, will prevail over the adaptive mechanisms (Fig. 5).

\section{MUSCLE DYSFUNCTION IN OTHER RESPIRATORY CONDITIONS}

\section{Cystic Fibrosis}

Patients with cystic fibrosis (CF) may develop respiratory muscle dysfunction (decreased strength and endurance) as a result of several contributing factors such as airflow limitation, hyperinflation, malnutrition, chronic infection, genetic predisposition, and medication ${ }^{69}$. 
Indeed, skeletal muscle weakness and exercise intolerance are prevalent in patients with $\mathrm{CF}^{70}$. Moreover, poor exercise tolerance, which is an independent risk factor of morbidity and mortality in patients with $\mathrm{CF}^{69,71}$, was commonly associated with impaired lung function, nutritional status, chronic inflammation, and infection ${ }^{69,71,72}$. Exercise aerobic training, inspiratory muscle training, and noninvasive ventilation, aside from dietary and pharmacological interventions, are currently available strategies to alleviate respiratory muscle dysfunction in CF patients ${ }^{69}$.

\section{Idiopathic Pulmonary Fibrosis}

It remains unknown whether patients with idiopathic pulmonary fibrosis (IPF) may develop muscle weakness of either respiratory or limb muscles during the course of the disease. Nonetheless, it was previously shown that in a series of patients with emphysema, IPF, and neuromuscular disease, respiratory muscle strength and gas exchange were similarly reduced ${ }^{73}$. On the other hand, reduced quadriceps force has been reported in IPF patients and was a predictor of exercise capacity (as measured by oxygen uptake) ${ }^{74}$.

\section{Scoliosis}

In a previous investigation ${ }^{75}$, patients with severe scoliosis exhibited significant quadriceps muscle weakness and alterations in the structure of the vastus lateralis compared to healthy age-matched sedentary controls. Furthermore, compared to healthy age-matched controls, a significant decrease in respiratory and limb muscle function was also observed in patients with adolescent idiopathic scoliosis that was associated with poorer exercise capacity, regardless of lung function ${ }^{76}$. Indeed, patients with adolescent idiopathic scoliosis exhibited significant alterations in body composition $^{77,78}$.

\section{Pulmonary Arterial Hypertension}

Skeletal muscle abnormalities have been demonstrated in patients with pulmonary arterial hypertension $\mathrm{PAH}^{79-81}$. As in COPD, skeletal muscle weakness in $\mathrm{PAH}$ patients leads to increased dyspnoea, fatigue, poor exercise tolerance, and impaired quality of life $\mathrm{e}^{79-81}$. Similarly, a switch to a less fatigue-resistant phenotype (lower proportions of slowtwitch fibres) and increased anaerobic metabolism have been demonstrated in the lower limb muscles of patients with $\mathrm{PAH}^{82-84}$. Furthermore, an anabolic/catabolic imbalance (increased proteolytic markers and reduced mitochondrial ATP production) has been recently demonstrated in the gastrocnemius and blood in an experimental model of $\mathrm{PAH}$ together with significant body and muscle weight loss ${ }^{85}$. In view of these findings, pulmonary rehabilitation and exercise training have recently gained a lot of attention in the scientific community to alleviate skeletal muscle dysfunction and exercise intolerance in patients with $\mathrm{PAH}^{80,86}$.

\section{EVIDENCE OF MUSCLE DYSFUNCTION IN CRITICALLY ILL PATIENTS}

Muscle atrophy and weakness have long been recognized as manifestations of severe illness. 
The impact of intensive care unit (ICU) acquired neuromuscular dysfunction is rather difficult to estimate ${ }^{9,87}$. In survivors of critical illnesses, functional disability and impaired quality of life have been related to neuromuscular complaints including persistent pain, contractures, and muscle weakness. Weakness affects the extremities and the diaphragm with relative sparing of the cranial nerves such that facial grimace is usually preserved. The finding of generalized weakness is extremely common in critically ill patients and warrants a review of aetiologies that are not necessarily identified in ICU settings.

Electrophysiological studies have demonstrated the presence of focal compressive mononeuropathy, polyneuropathy, and/or myopathy persisting from months to years after the acute critical illness. In the ICU acute setting, muscle weakness is associated with prolonged mechanical ventilation, failure to separate from the ventilator, delayed discharge from the ICU and hospital, and greater costs ${ }^{88-90}$. Recognition of neuromuscular dysfunction as an important and potentially long-term manifestation of critical illness has led to the identification of preventive or therapeutic interventions including glycemic control, measures focused on early mobility, as well as physical and occupational therapy.

Despite the difficulties encountered to articulate a comprehensive diagnostic nomenclature and classification, an effort has been made to establish the following definitions. First of all, the term ICU-acquired weakness (ICU-AW) refers to clinically detected weakness in critically ill patients in whom there is no plausible aetiology other than critical illness. Patients with ICU-AW and documented polyneuropathy and/or myopathy are classified into three categories: (i) critical illness polyneuropathy (CIP) refers to patients with ICU-AW who have electrophysiological evidence of an axonal polyneuropathy ${ }^{91}$; (ii) critical illness myopathy (CIM) refers to patients with ICU-AW who have electrophysiologically and/or histologically defined myopathy ${ }^{92}$; and (iii) critical illness neuromyopathy (CINM) indicates patients who have electrophysiological and/or histological findings of coexisting CIP and CIM.

Critical illness myopathy is identified in patients who meet the criteria for ICU-AW and who have myopathy features on electromyography (EMG) recorded during voluntary muscle contraction and/or myopathy muscle biopsy $^{92}$. Physical examination findings are not usually specific. It is difficult to differentiate CIM from CIP, except in fully awake patients in whom the documentation of a new distal sensory loss is suggestive of CIP. However, in patients who are unable to voluntarily contract muscle, EMG and/or nerve conduction studies differentiate poorly between CIP and CIM, but preserved neuronal action potential amplitudes are suggestive of CIM without coexisting CIP. In patients unable to voluntarily contract, confirmation of CIM is based on muscle biopsy procedures and/or direct muscle stimulation. Thick filament (myosin) loss, type II fibre atrophy, and necrosis are usually counted among the most relevant pathological features in CIM. Besides, increased blood creatine kinase has also been shown in CIM. A differential diagnosis should always be conducted between CIM and other conditions such as disuse muscle atrophy, steroid myopathy, cachexia, rhabdomyolysis, and decompensation of primary muscle disorders. 
Although there is no diagnostic gold standard for ICU-AW or its categories, several measures and clinical tests should be performed in order to quickly identify the problem in the critically ill patient ${ }^{93}$.

\section{CONCLUDING REMARKS}

Skeletal muscle dysfunction is a major systemic manifestation in patients with respiratory conditions. In the last two decades, most of the research in this field has been devoted to the elucidation of the prevalence and aetiology of muscle dysfunction in COPD. Muscle weakness and wasting predict morbidity and mortality in patients with COPD. However, the mechanisms potentially linking muscle dysfunction and the primary organ disease remain to be fully elucidated. Current avenues of research in this arena focus on the identification of biological mechanisms that may help design novel therapeutic strategies to better treat muscle dysfunction in COPD, regardless of the lung disease. Moreover, interest in elucidation of the pathophysiology of muscle dysfunction in the critically ill patient is also growing. Evidence emerging from the field of COPD muscle dysfunction should be used as a model for enhancing current knowledge on the specific role of muscle weakness and dysfunction in patients bearing other chronic respiratory disorders, in which muscle dysfunction is prevalent, as well as in critical illness. Importantly, the specific contribution to muscle dysfunction of therapies commonly prescribed in patients with chronic respiratory disorders and critical illness, such as systemic corticosteroids and immunosuppressants, should also be the focus of future research in these patients.
Identification of skeletal muscle dysfunction should be included in the routine assessment of patients with chronic respiratory disorders and in critical care settings.

\section{DECLARATION OF INTEREST}

CIBERES, FIS 11/02029 (FEDER), FIS 14/00713 (FEDER), SEPAR 2014, FUCAP 2009, FUCAP 2011, and FUCAP 2012 have contributed to support part of the research described in this review.

\section{ACKNOWLEDGEMENTS}

Professor Joaquim Gea is gratefully acknowledged for his help with part of the design of figures 2-5.

\section{REFERENCES}

1. Miravitlles M, Calle M, Soler-Cataluna JJ. Clinical phenotypes of COPD identification, definition and implications for guidelines. Arch Bronconeumol. 2012;48:86-98.

2. Miravitlles M, Soler-Cataluna JJ, Calle M et al. Spanish Guideline for COPD (GesEPOC). Update 2014. Arch Bronconeumol. 2014;50(Suppl 1):1-16.

3. Maltais F, Decramer M, Casaburi R et al. An official American Thoracic Society/European Respiratory Society statement: update on limb muscle dysfunction in chronic obstructive pulmonary disease. Am J Respir Crit Care Med. 2014;189:e15-62.

4. Gea J, Martinez-Llorens J, Barreiro E. [Nutritional abnormalities in chronic obstructive pulmonary disease.]. Med Clin (Barc ). 2014;143:78-84.

5. Marquis K, Debigare R, Lacasse $Y$ et al. Midthigh muscle cross-sectional area is a better predictor of mortality than body mass index in patients with chronic obstructive pulmonary disease. Am J Respir Crit Care Med 2002;166:809-13.

6. Shrikrishna D, Patel M, Tanner RJ et al. Quadriceps wasting and physical inactivity in patients with COPD. Eur Respir J. 2012;40:1115-22.

7. Swallow EB, Reyes D, Hopkinson NS et al. Quadriceps strength predicts mortality in patients with moderate to severe chronic obstructive pulmonary disease. Thorax. 2007;62:115-20.

8. Gayan-Ramirez G, Decramer M. Mechanisms of striated muscle dysfunction during acute exacerbations of COPD. J Appl Physiol. 2013;114:1291-9.

9. Puthucheary Z, Harridge S, Hart N. Skeletal muscle dysfunction in critical care: wasting, weakness, and rehabilitation strategies. Crit Care Med 2010;38:S676-82. 
10. Gosselink R, Troosters T, Decramer M. Distribution of muscle weakness in patients with stable chronic obstructive pulmonary disease. J Cardiopulm Rehabil. 2000;20:353-60.

11. Gosselink R, De VJ, van den Heuvel SP, Segers J, Decramer M, Kwakkel G. Impact of inspiratory muscle training in patients with COPD: what is the evidence? Eur Respir J. 2011;37:416-25.

12. Simpson K, Killian K, McCartney N, Stubbing DG, Jones NL. Randomised controlled trial of weightlifting exercise in patients with chronic airflow limitation. Thorax. 1992;47:70-5

13. Decramer M, Gosselink R, Troosters T, Verschueren M, Evers G. Muscle weakness is related to utilization of health care resources in COPD patients. Eur Respir J. 1997;10:417-23.

14. Bachasson D, Wuyam B, Pepin JL, Tamisier R, Levy P, Verges S. Quadriceps and respiratory muscle fatigue following high-intensity cycling in COPD patients. PLoS One. 2013;8:e83432.

15. Burtin C, Saey D, Saglam M et al. Effectiveness of exercise training in patients with COPD: the role of muscle fatigue. Eur Respir J. 2012;40:338-44.

16. Coronell C, Orozco-Levi M, Mendez R, Ramirez-Sarmiento A, Galdiz JB, Gea J. Relevance of assessing quadriceps endurance in patients with COPD. Eur Respir J. 2004;24:129-36.

17. Mador MJ, Bozkanat E, Kufel TJ. Quadriceps fatigue after cycle exercise in patients with COPD compared with healthy control subjects. Chest. 2003;123:1104-11.

18. Marquis N, Debigare R, Bouyer L et al. Physiology of walking in patients with moderate to severe chronic obstructive pulmonary disease. Med Sci Sports Exerc. 2009;41:1540-8.

19. Barreiro E, Bustamante V, Cejudo P et al. Guidelines for the evaluation and treatment of muscle dysfunction in patients with chronic obstructive pulmonary disease. Arch Bronconeumol. 2015;51:384-95.

20. Barreiro E, Gea J. Respiratory and limb muscle dysfunction in COPD. COPD. 2015;12:413-26.

21. Barreiro E, Gea J. Molecular and biological pathways of skeletal muscle dysfunction in chronic obstructive pulmonary disease. Chron Respir Dis. 2016. [Epub ahead of print].

22. Gea J, Agusti A, Roca J. Pathophysiology of muscle dysfunction in COPD. J Appl Physiol. 2013;114:1222-34.

23. Seymour JM, Spruit MA, Hopkinson NS et al. The prevalence of quadriceps weakness in COPD and the relationship with disease severity. Eur Respir J. 2010;36:81-8.

24. Levine S, Bashir MH, Clanton TL, Powers SK, Singhal S. COPD elicits remodeling of the diaphragm and vastus lateralis muscles in humans. J Appl Physiol. 2013;114:1235-45.

25. Similowski T, Yan S, Gauthier AP, Macklem PT, Bellemare F. Contractile properties of the human diaphragm during chronic hyperinflation. $\mathrm{N}$ Engl J Med. 1991;325:917-23.

26. Ramirez-Sarmiento A, Orozco-Levi M, Barreiro E et al. Expiratory muscle endurance in chronic obstructive pulmonary disease. Thorax. 2002;57:132-6.

27. Ramirez-Sarmiento A, Orozco-Levi M, Guell R et al. Inspiratory muscle training in patients with chronic obstructive pulmonary disease: structural adaptation and physiologic outcomes. Am J Respir Crit Care Med. 2002;166:1491-7.

28. Vilaro J, Ramirez-Sarmiento A, Martinez-Llorens JM et al. Global muscle dysfunction as a risk factor of readmission to hospital due to COPD exacerbations. Respir Med. 2010;104:1896-902.

29. Crul T, Testelmans D, Spruit MA et al. Gene expression profiling in vastus lateralis muscle during an acute exacerbation of COPD. Cell Physiol Biochem. 2010;25:491-500.

30. Pitta F, Troosters T, Probst VS, Spruit MA, Decramer M, Gosselink R. Physical activity and hospitalization for exacerbation of COPD. Chest. 2006;129:536-44.

31. Spruit MA, Gosselink R, Troosters T et al. Muscle force during an acute exacerbation in hospitalised patients with COPD and its relationship with CXCL8 and IGF-I. Thorax. 2003;58:752-6.

32. Decramer M, de B, V, Dom R. Functional and histologic picture of steroid-induced myopathy in chronic obstructive pulmonary disease. Am J Respir Crit Care Med. 1996;153:1958-64.
33. Fermoselle C, Rabinovich R, Ausin P et al. Does oxidative stress modulate limb muscle atrophy in severe COPD patients? Eur Respir J. 2012;40:851-62.

34. Puig-Vilanova E, Martinez-Llorens J, Ausin P, Roca J, Gea J, Barreiro E. Quadriceps muscle weakness and atrophy are associated with a differential epigenetic profile in advanced COPD. Clin Sci (Lond). 2015;128:905-21.

35. Puig-Vilanova E, Rodriguez DA, Lloreta J et al. Oxidative stress, redox signaling pathways, and autophagy in cachectic muscles of male patients with advanced COPD and lung cancer. Free Radic Biol Med. 2015;79:91-108.

36. Torres SH, Montes de OM, Loeb E, Mata A, Hernandez N. Gender and skeletal muscle characteristics in subjects with chronic obstructive pulmonary disease. Respir Med. 2011;105:88-94.

37. Lexell J, Downham D. What is the effect of ageing on type 2 muscle fibres? J Neurol Sci. 1992;107:250-1.

38. Kelsen SG, Ference M, Kapoor S. Effects of prolonged undernutrition on structure and function of the diaphragm. J Appl Physiol. 1985;58:1354-9.

39. Dekhuijzen PN, Decramer M. Steroid-induced myopathy and its significance to respiratory disease: a known disease rediscovered. Eur Respir J. 1992;5:997-1003.

40. Jobin J, Maltais F, Doyon JF et al. Chronic obstructive pulmonary disease: capillarity and fiber-type characteristics of skeletal muscle. J Cardiopulm Rehabil. 1998;18:432-7.

41. Whittom F, Jobin J, Simard PM et al. Histochemical and morphologica characteristics of the vastus lateralis muscle in patients with chronic obstructive pulmonary disease. Med Sci Sports Exerc. 1998;30:1467-74.

42. Maltais F, LeBlanc $P$, Whittom F et al. Oxidative enzyme activities of the vastus lateralis muscle and the functional status in patients with COPD. Thorax. 2000;55:848-53.

43. Saey D, Michaud A, Couillard A et al. Contractile fatigue, muscle morphometry, and blood lactate in chronic obstructive pulmonary disease. Am J Respir Crit Care Med. 2005;171:1109-15.

44. Saey D, Lemire BB, Gagnon P et al. Quadriceps metabolism during constan workrate cycling exercise in chronic obstructive pulmonary disease. J App Physiol. 2011;110:116-24.

45. Naimi AI, Bourbeau J, Perrault $\mathrm{H}$ et al. Altered mitochondrial regulation in quadriceps muscles of patients with COPD. Clin Physiol Funct Imaging 2011;31:124-31.

46. Puente-Maestu L, Perez-Parra J, Godoy R et al. Abnormal transition pore kinetics and cytochrome $\mathrm{C}$ release in muscle mitochondria of patients with chronic obstructive pulmonary disease. Am J Respir Cell Mol Biol. 2009;40:746-50.

47. Puente-Maestu L, Lazaro A, Tejedor A et al. Effects of exercise on mitochondrial DNA content in skeletal muscle of patients with COPD. Thorax 2011;66:121-7.

48. Takabatake N, Nakamura $\mathrm{H}$, Abe $\mathrm{S}$ et al. The relationship between chronic hypoxemia and activation of the tumor necrosis factor-alpha system in patients with chronic obstructive pulmonary disease. Am J Respir Crit Care Med. 2000;161:1179-84.

49. Caron MA, Theriault ME, Pare ME, Maltais F, Debigare R. Hypoxia alters contractile protein homeostasis in L6 myotubes. FEBS Lett. 2009;583:1528-34

50. Chandel NS, McClintock DS, Feliciano CE et al. Reactive oxygen species generated at mitochondrial complex III stabilize hypoxia-inducible factor-1alpha during hypoxia: a mechanism of $\mathrm{O} 2$ sensing. J Biol Chem 2000;275:25130-8.

51. Koechlin C, Maltais F, Saey D et al. Hypoxaemia enhances peripheral muscle oxidative stress in chronic obstructive pulmonary disease. Thorax. 2005;60:834-41.

52. de Theije C, Costes F, Langen RC, Pison C, Gosker HR. Hypoxia and muscle maintenance regulation: implications for chronic respiratory disease Curr Opin Clin Nutr Metab Care. 2011;14:548-53.

53. Jaitovich A, Angulo M, Lecuona E et al. High CO2 levels cause skeleta muscle atrophy via AMP-activated kinase (AMPK), FoxO3a protein, and muscle-specific Ring finger protein 1 (MuRF1). J Biol Chem. 2015;290:9183-94.

54. Barreiro E, de la Puente B, Minguella J et al. Oxidative stress and respiratory muscle dysfunction in severe chronic obstructive pulmonary disease. Am J Respir Crit Care Med. 2005;171:1116-24. 
55. Barreiro E, Galdiz JB, Marinan M, Alvarez FJ, Hussain SN, Gea J. Respiratory loading intensity and diaphragm oxidative stress: N-acetyl-cysteine effects. J Appl Physiol. 2006;100:555-63.

56. Barreiro E, Schols AM, Polkey MI et al. Cytokine profile in quadriceps muscles of patients with severe COPD. Thorax. 2008;63:100-7.

57. Barreiro E, Rabinovich R, Marin-Corral J, Barbera JA, Gea J, Roca J. Chronic endurance exercise induces quadriceps nitrosative stress in patients with severe COPD. Thorax. 2009;64:13-9.

58. Barreiro E, Peinado VI, Galdiz JB et al. Cigarette smoke-induced oxidative stress: A role in chronic obstructive pulmonary disease skeletal muscle dysfunction. Am J Respir Crit Care Med. 2010;182:477-88.

59. Bustamante V, Casanova J, Lopez de SE et al. Redox balance following magnetic stimulation training in the quadriceps of patients with severe COPD. Free Radic Res. 2008;42:939-48.

60. Koechlin C, Couillard A, Simar D et al. Does oxidative stress alter quadriceps endurance in chronic obstructive pulmonary disease? Am J Respir Crit Care Med. 2004;169:1022-7.

61. Rodriguez DA, Kalko S, Puig-Vilanova E et al. Muscle and blood redox status after exercise training in severe COPD patients. Free Radic Biol Med. 2012;52:88-94

62. Barreiro E, Ferrer D, Sanchez F et al. Inflammatory cells and apoptosis in respiratory and limb muscles of patients with COPD. J Appl Physiol. 2011;111:808-17

63. Barreiro E, del Puerto-Nevado L, Puig-Vilanova E et al. Cigarette smoke-induced oxidative stress in skeletal muscles of mice. Respir Physiol Neurobiol. 2012;182:9-17.

64. Montes de OM, Loeb E, Torres SH, De SJ, Hernandez N, Talamo C. Peripheral muscle alterations in non-COPD smokers. Chest. 2008;133:13-8.

65. Barreiro E, Sznajder JI. Epigenetic regulation of muscle phenotype and adaptation: a potential role in COPD muscle dysfunction. J Appl Physiol. 2013;114:1263-72.

66. Barreiro E, Gea J. Epigenetics and muscle dysfunction in chronic obstructive pulmonary disease. Transl Res. 2015;165:61-73.

67. Puig-Vilanova E, Ausin P, Martinez-Llorens J, Gea J, Barreiro E. Do epigenetic events take place in the vastus lateralis of patients with mild chronic obstructive pulmonary disease? PLoS One. 2014;9:e102296.

68. Puig-Vilanova E, Aguilo R, Rodriguez-Fuster A, Martinez-Llorens J, Gea J, Barreiro E. Epigenetic mechanisms in respiratory muscle dysfunction of patients with chronic obstructive pulmonary disease. PLoS One. 2014;9:e111514.

69. Dassios T. Determinants of respiratory pump function in patients with cystic fibrosis. Paediatr Respir Rev. 2015;16:75-9.

70. Troosters T, Langer D, Vrijsen B et al. Skeletal muscle weakness, exercise tolerance and physical activity in adults with cystic fibrosis. Eur Respir J. 2009;33:99-106

71. Moorcroft AJ, Dodd ME, Webb AK. Exercise testing and prognosis in adult cystic fibrosis. Thorax. 1997;52:291-3.

72. van de Weert-van Leeuwen PB, Hulzebos HJ, Werkman MS et al. Chronic inflammation and infection associate with a lower exercise training response in cystic fibrosis adolescents. Respir Med. 2014;108:445-52.

73. Nishimura Y, Hida W, Taguchi O et al. Respiratory muscle strength and gas exchange in neuromuscular diseases: comparison with chronic pulmonary emphysema and idiopathic pulmonary fibrosis. Tohoku J Exp Med. 1989;159:57-68
74. Nishiyama O, Taniguchi H, Kondoh Y et al. Quadriceps weakness is related to exercise capacity in idiopathic pulmonary fibrosis. Chest. 2005;127: 2028-33.

75. Swallow EB, Barreiro E, Gosker H et al. Quadriceps muscle strength in scoliosis. Eur Respir J. 2009;34:1429-35.

76. Martinez-Llorens J, Ramirez M, Colomina MJ et al. Muscle dysfunction and exercise limitation in adolescent idiopathic scoliosis. Eur Respir J. 2010;36:393-400.

77. Perez-Prieto D, Sanchez-Soler JF, Martinez-Llorens J et al. Poor outcome and satisfaction in adolescent idiopathic scoliosis surgery: the relevance of the body mass index and self-image. Eur Spine J. 2015;24:276-80.

78. Ramirez M, Martinez-Llorens J, Sanchez JF et al. Body composition in adolescent idiopathic scoliosis. Eur Spine J. 2013;22:324-9.

79. Malenfant S, Potus F, Mainguy V et al. Impaired skeletal muscle oxygen ation and exercise tolerance in pulmonary hypertension. Med Sci Sport Exerc. 2015;47:2273-82.

80. Panagiotou M, Peacock AJ, Johnson MK. Respiratory and limb muscle dysfunction in pulmonary arterial hypertension: a role for exercise training? Pulm Circ. 2015;5:424-34.

81. Manders E, Rain S, Bogaard HJ et al. The striated muscles in pulmonary arterial hypertension: adaptations beyond the right ventricle. Eur Respir J. 2015;46:832-42.

82. Batt J, Ahmed SS, Correa J, Bain A, Granton J. Skeletal muscle dysfunction in idiopathic pulmonary arterial hypertension. Am J Respir Cell Mol Biol. 2014;50:74-86

83. Bauer R, Dehnert C, Schoene P et al. Skeletal muscle dysfunction in patients with idiopathic pulmonary arterial hypertension. Respir Med. 2007;101:2366-9.

84. Mainguy V, Maltais F, Saey D et al. Peripheral muscle dysfunction in idiopathic pulmonary arterial hypertension. Thorax. 2010;65:113-7.

85. Moreira-Goncalves D, Padrao AI, Ferreira R et al. Signaling pathways underlying skeletal muscle wasting in experimental pulmonary arterial hypertension. Biochim Biophys Acta. 2015;1852:2722-31.

86. Saglam M, Arikan H, Vardar-Yagli $\mathrm{N}$ et al. Inspiratory muscle training in pulmonary arterial hypertension. J Cardiopulm Rehabil Prev. 2015;35:198-206.

87. De Jonghe B, Sharshar T, Lefaucheur JP et al. Paresis acquired in the intensive care unit: a prospective multicenter study. JAMA. 2002;288:2859-67.

88. De Jonghe B, Bastuji-Garin S, Durand MC et al. Respiratory weakness is associated with limb weakness and delayed weaning in critical illness. Crit Care Med. 2007;35:2007-15.

89. Garnacho-Montero J, Amaya-Villar R, Garcia-Garmendia JL, Madrazo-Osuna J, Ortiz-Leyba C. Effect of critical illness polyneuropathy on the withdrawal from mechanical ventilation and the length of stay in septic patients. Crit Care Med. 2005;33:349-54.

90. Herridge MS, Cheung AM, Tansey CM, Matte-Martyn A, Diaz-Granados $\mathrm{N}$, Al-Saidi $\mathrm{F}$ et al. One-year outcomes in survivors of the acute respiratory distress syndrome. N Engl J Med. 2003 Feb 20;348(8):683-93. doi 10.1056/NEJMoa022450 [doi];348/8/683 [pii].

91. Bolton CF, Gilbert JJ, Hahn AF, Sibbald WJ. Polyneuropathy in critically ill patients. J Neurol Neurosurg Psychiatry. 1984;47:1223-31.

92. Lacomis D, Zochodne DW, Bird SJ. Critical illness myopathy. Muscle Nerve. 2000;23:1785-8

93. Connolly BA, Jones GD, Curtis AA et al. Clinical predictive value of manual muscle strength testing during critical illness: an observational cohor study. Crit Care. 2013;17:R229. 